\title{
Multivariable modeling of an innovative hybrid solar-gas dryer
}

Zoukit, A.; Elferouali, H.; Salhi, I.; Doubabi, S.; Abdenouri, N*.

LSET, Cadi AYYAD University, Marrakech 4000 Morocco

*E-mail of the corresponding author: n.abdenouri@uca.ac.ma

\begin{abstract}
The main goal of this paper, is to propose a multivariable control model (MM) issued from CFD study of an innovative hybrid solar-gas dryer to simulate the drying chamber temperature in three modes of operation: Solar mode, Gas mode and hybrid mode. There is an indirect heating of drying air instead of direct heating inside the drying chamber. The air temperature obtained by CFD is still closed to one obtained by multivariable model (MM) with an RMSE under 2.31. the proposed multivariable model leads to a quick output parameters estimation related to each clilmate conditions and so, to an easy control of a hybrid solar dryer.
\end{abstract}

Keywords: Hybrid dryer; Multivariable model; solar dryer simulation; solar dryer control; Least square methods. 


\section{Introduction}

Currently, solar energy is an important alternative source of energy. It is free, abundant, inexhaustible and non-polluant in comparison with higher price and shortage of fossil fuels [1]. Solar drying of agriculture products is one of the most important potential applications in the countries in development [2]. Actually, framers and citizens dry crops such as (date, grapes, tea, menth and tomato) by spreading them in thin layers, on mats, paved ground or in the field, exposing them directly to the sun radiation. The drying by his archaic way affect strongly the quality of dried product and leads to a large post-harvest deterioration [3]. Indirect solar dryer can easily overcome these issues while using solar radiation as energy source for drying process [4].

In the other hand, the solar dryers are still limited by the intermittent fact and it could not be effective without the presence of another source. However, to enhance the quality of dried products and to optimize energy consumption, many works were carried out to design a dryer where the hot air is produced regularly and where the drying parameters (temperature, humidity and airflow) are under control.

In contrast, hybrid solar-gas dryers are widly used for drying a variety of products. They operate with solar energy in addition to an other energy source which is gas power. According to the literature survey, many works used an external boiler where the gas is burned and the hot air is produced and conducted to the drying chamber [5]. This technique requires a huge operational space and regular maintenance which make the drying system more complex. In other works [6,7], conceived a hybrid solar-gas dryer using a gas burner inside the drying chamber where the dried product adsorb many gaseous species resulting from the combustion of the gas.

Some reaserchers have already employed CFD to simulate the temperature, air velocity and relative humidity at various locations inside the drying chamber [8,9,10]. However, due to the complexity in the drying chamber, obtaining accurate results by CFD study requires a high level of grid density so a performing computational ressources [11].

This paper is proposed to design and simulate a hybrid indirect solar-gas dryer to best controlling drying process. The indirect heating of air inside the drying chamber guarantees the safety and improves the quality of the dried product. CFD modeling of the hybrid dryer is established in order to investigate its thermal performances in term of the threshold of drying temperature. A multivariable model issued from CFD simulation was developed based on non linear least square methods. The developed model leads to predict the drying temperature inside the drying chamber with a huge reduction in simulation time and leads also to easly synthesize a control system of the drying temperature. 


\section{Materials and Methods}

The hybrid solar-gas dryer was designed and simulated using Solidworks Flow simulation developed by Dassault systems Solidworks crops. The dryer consists of a cubic drying chamber of $(1 \mathrm{~m} * 1 \mathrm{~m} * 1 \mathrm{~m})$, fitted with perforated plate trays of stainless steel. The drying chamber is combined with a solar-gas collector used to generate regularely the hot air. The solar part of the collector is a finned plate solar air heater, the absorber's length is $\mathrm{L}=2 \mathrm{~m}$ and its width is $\mathrm{W}=0.95 \mathrm{~m}$ and it is made from aluminium. The top side of the absorber is painted with matt black glycerpphtalic lacquer. The absorber containes 24 fins made from $1 \mathrm{~mm}$ thick aluminium. The top side of the absorber is covered by $3 \mathrm{~mm}$ glass with a separation of $0.05 \mathrm{~m}$ with the absorber. The solar collector is fitted with a heat exchanger (metallic sheet) placed under the absorber. The back up heating system is a set of 9 burners located under the exchanger and monitored by a valve. The drying air passes through the flat plate collector between the absorber and the exchanger. The synoptic of the hybrid dryer is presented in Fig. 1.

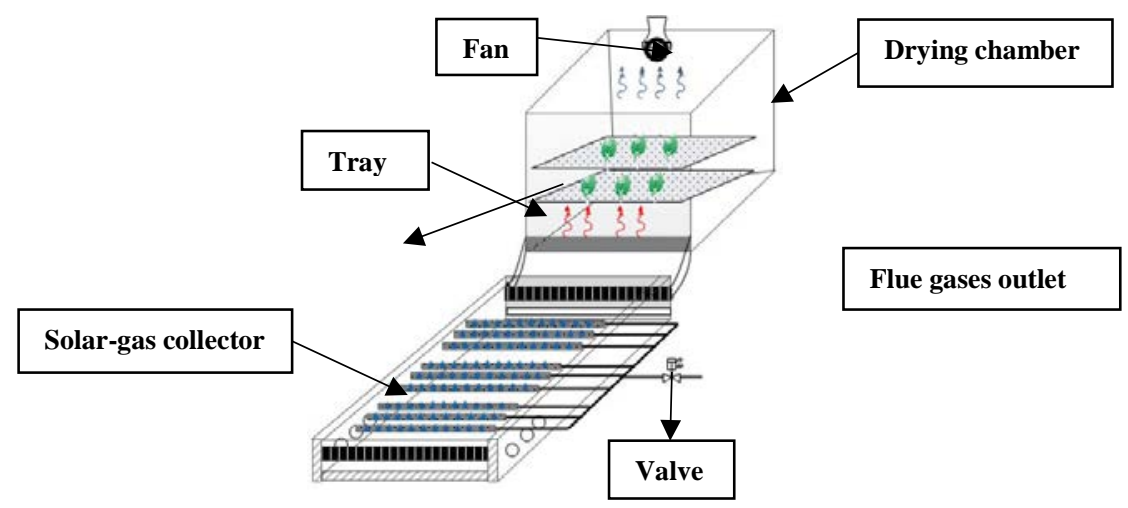

Fig. 1 Synoptic of the hybrid solar-gas dryer

\section{Simulation appraoch}

CFD is used for air temperature and airflow distribution inside the drying chamber accomplished by 3-dimentional governing equation (mass, momentum and energy equation) along with initial and boundary conditions under transient and turbulent flow assumptions. Since the small temperature variations, the hot air is considered as incomprehensible flow.

\subsection{Simulation model}

Fig. 2 demonstrates the 3-D solar-gas hybrid dryer simulation model. This model used single component model with assumptions of incompressible and unsteady-state flow. Simulations were conducted using a grid density of $(1,906,000)$. 

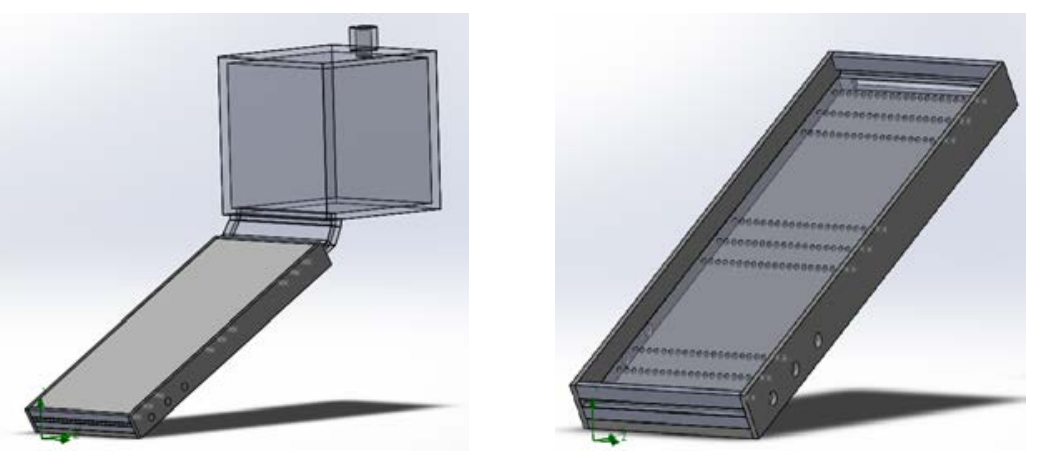

Fig. 2 CFD conception of the hybrid dryer

\subsection{Initial and boundry conditions.}

The initial temperatures of chamber walls, surface of tubular burners and inside air were taken equal to $25^{\circ} \mathrm{C}$. The inlet air velocity was $0.025 \mathrm{~kg} \mathrm{~s}^{-1}$ calculated from the flow rate of the ventilating fan while the inlet temperature and the relative humidity were assumed to be at $25^{\circ} \mathrm{C}$ and $50 \%$ respectively. These values are typical average ambient ones in Marrakesh at Morocco. The flames of the burners are modeled as volume heat sources located under a metallic sheet. The flames' diameter is $1 \mathrm{~cm}$ and their number is 216 (24 flames for each burner). Hence, the power of each flame is $P g / 216$, with $P g$ is the total gas power $(W)$. The solar-gas collector is fitted with apertures in the both sides and in the outlet allowing the natural circulation of the necessary air for total combustion.

\section{Multivariable model of the hybrid solar-gas dryer}

In this paper, a hybrid solar-gas dryer designed in SolidWorks is consedred as a non linear multivariable system. Solar radiation $(G)$, gas power $(P g)$ and airflow $(\dot{m})$ are considered as the main inputs of the dryer and the drying chamber temperature $(T c h)$ is considered as output parameter.

\subsection{Static characteristics}

The static characteristics of the dryer are necessary for a description of the behavior of the system. It consists on measuring the output on the basis of inputs in steady state. Statics characteristics of the dryer lead to easily identify the linear zones and operating points which help for shapping the input signals for modeling the system.

The average drying temperature (Tch) was measured on the basis of solar radiation, gas power and airflow. The measurements were carried out in the steady state.

The static characteristic of (Tch) on basis of $(G)$ was built varying the solar radiation in a range of $0-1200 \mathrm{~W} \mathrm{~m}{ }^{-2}$ while considering gas power and airflow constant $(P g=2 \mathrm{~kW}$ and $\dot{m}=$ $\left.0.025 \mathrm{~kg} \mathrm{~s}^{-1}\right)$. wherease, the static characteristic of $(T c h)$ on basis of $(P g)$ was built varying 
the gas power in a range of $(0-5 \mathrm{~kW})$ while considering solar radiation and airflow constant ( $G=700 \mathrm{~W} \mathrm{~m}^{-2}$ and $\dot{m}=0.025 \mathrm{~kg} \mathrm{~s}^{-1}$ ). The static characteristic of (Tch) on basis of $(\dot{m})$ was built varying the airflow in a range of $\left(0.005-0.07 \mathrm{~kg} \mathrm{~s}^{-1}\right)$ while considering solar radiation and gas power constant ( $G=700 \mathrm{~W} \mathrm{~m}^{-2}$ and $\left.P g=3 \mathrm{~kW}\right)$ (Fig. 3).
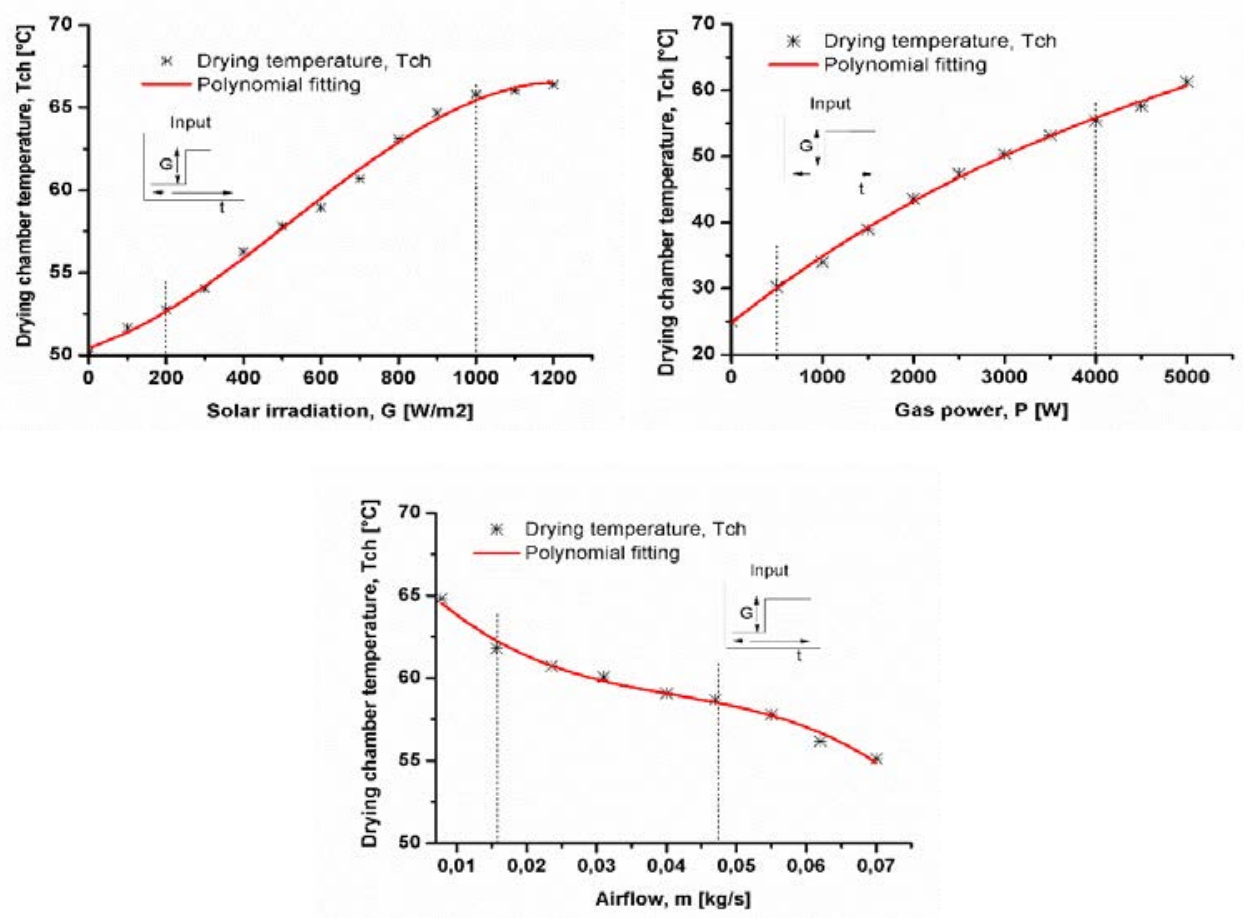

Fig. 3 Static characteristics of the hybrid dryer

\subsection{Generation of input signals}

The used input test signals for modeling the dryer are Pseudo Random Binary Sequences (PRBS). The PRBS is a two state signal varying between the maximum and the minimum points of each linear zone. In addition, at least one of the PRSB pulses should be greater than the system rise time [12].

The measurements were conducted in transitory state. The time simulation was set to 20 hours of operation.

The obtained input/output were loaded into the system identification Toolbox of Matlab environment using (Ident) in order to identify the linear model of the hybrid dryer. The system identification provided using Matlab allows building mathematical models of a dynamic system based on non-linear least squares estimation method. 
The simulation result of the identified linear multivariable model fitted the CFD simulation with $90 \%$ of accuracy. for control purpose, this is an accurate model.

The hybrid dryer state space multivariable model is represented by:

$A=\left[\begin{array}{cc}-0.0030 & -0.0202 \\ -0.0141 & -0.1701\end{array}\right] ; B\left[\begin{array}{ccc}-0.00046 & 6.87 e^{-6} & 4.959 e^{-6} \\ -0.00180 & 2.66 e^{-5} & -0.00039\end{array}\right] ; C=[238.4-0.56]$

To verify the validity and the effectiveness of the proposed multivariable model. The temperature profile inside the drying chamber obtained by CFD simulation is compared with the temperature predicted by multivariable model. The CFD average drying chamber temperature at three operating modes of the solar dryer (solar mode $\left(900 \mathrm{~W} \mathrm{~m}^{-2}\right.$ ), gas mode (3kW) and hybrid mode (600W $\left.\mathrm{m}^{-2} ; 2 \mathrm{~kW}\right)$ ) was considered for comparison with the multivariable model simulation. CFD and Multivariable model simulation results were plotted against clock time as shown in Figs. (4a-4b-4c). The temperature profile of CFD simulation was almost similar to that of Multivariable model. The root main square error RMSE remains under 2.31 .

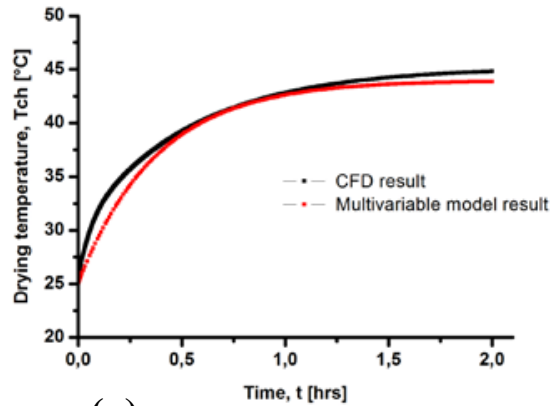

(a)

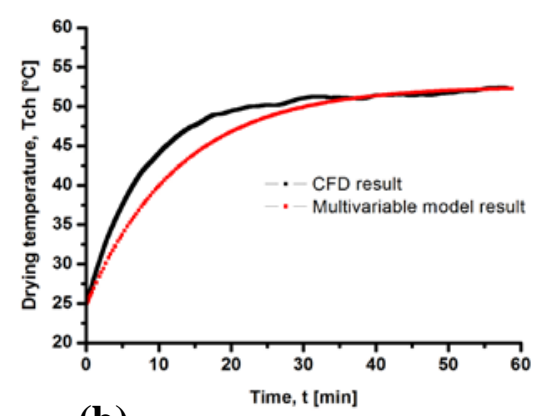

(b)

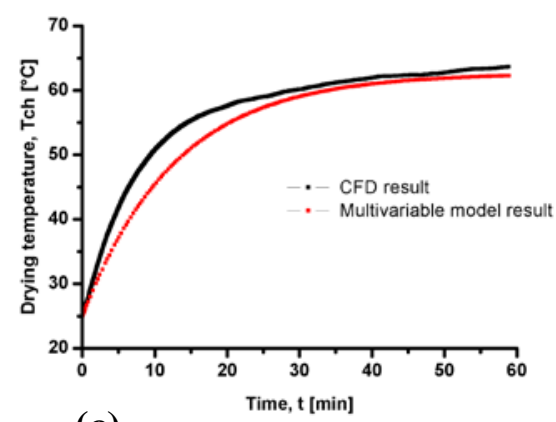

(c)

Fig. 4 Comparison between the simulated CFD and MM output; a. solar mode; b. hybrid mode; c. gas mode 


\section{Conclusion}

A multivariable model of the hybrid dryer for predicting the drying temperature was developed based on nonlinear least square methods taking into account solar radiation, gas power and airflow as the main input parameters. The predicted temperatures by multivariable model were compared with the CFD ones based on mean root square error (RMSE). From the values of RMSE (0.91-2.38), it is inferred that the predicted values by multivariable model are in harmony with the observed values by CFD. The multivariable model leads to predict the temperature with a remarkable reduction in simulation time. The threshold of drying temperature has been investigated in three operating modes of the dryer: solar mode, gas mode and hybrid mode. The range of the reached temperature $\left(45.2^{\circ} \mathrm{C}, 53.4^{\circ} \mathrm{C}\right.$ and $62.4^{\circ} \mathrm{C}$ ) is suitable for drying a wide variety of products. The developed multivariable model will be useful to synthesize a temperature controller in order to control the drying temperature in a suitable range for the product to be dried and improves their quality.

\section{Aknoledgement}

This work was supported by the research institute for solar energy and new energies (IRESEN) as part of the project SSH and all of the authors are grateful to the IRESEN institute for its cooperation.

\section{References}

[1] Basunia, M.A.; Abe, T. Thin layer solar drying characteristics of rough rice under natural convection. Journal of Food Engineering 2001. 47(4), 295-301.

[2] Boughali, S.; Benmoussa, H.; Bouchekima, B.; Mennouche, D.; Bouguettaia, H.; Bechki, D. Crop drying by indirect active hybrid solar - Electrical dryer in the eastern Algerian Septentrional Sahara. Sol. Energy 2009. 83, 2223-2232.

[3] Bala, B.K.; Mondol, M.R.A.; Biswas, B.K.; Das Chowdury, B.L.; Janjai, S. Solar drying of pineapple using solar tunnel drier. Renewable Energy 2003. 28, 183-190.

[4] Madhlopa, A.; Ngwalo, G. Solar dryer with thermal storage and biomass back-up heater. Solar Energy 2007. 81, 449-462.

[5] Tadahmum Yassen A.; Hussain Al-Kayiem H. Experimental investigation and evaluation of hybrid solar/thermal dryer combined with supplementary recovery dryer. Solar Energy 2016. (134), 284-293.

[6] Oueslati H.; Benmbrouk S.; Mami A. Design and Installation of a Solar-Gas Tunnel dryer. The fifth International Renewable Energy Congress IREC 2014. 1-6.

[7] López-Vidaña E.; Méndez-Lagunas L.; Rodriguez-Ramirez J. Efficiency of a hybrid solar-gas dryer. Solar Energy 2013. (93), 23-31.

[8] Junchangpood A.; Chanvattana V.A. simulation of temperatures and velocities distribution of a hot-air stream of a rubber smoke sheet drying room using CFD. Conf. Mech. Eng. Netw. Thail 2007. 24, 1041-1047. 
[9] Tekasakul P.; Dejchanchaiwong R.; Tirawanichakul Y.; Tirawanichakul S. Threedimensional numerical modeling of heat and moisture transfer in natural rubber sheet drying process. Drying Technology 2015. 33, 1124-1137.

[10] Promtong M.; Tekasakul P. CFD study of flow in natural rubber smoking room: I. validation with the present smoking-room. Appl. Therm. Eng 2007. 27, 2113-2121.

[11] Sonthikun S.; Chairat P.; Fardsin K.; Kirirat P.; Kumar A.; Tekasakul P. Computational fluid dynamic analysis of innovative design of solar-biomass hybrid dryer: An experimental validation. Renewable Energy 2016. 92, 185-191.

[12] Ioan Dore L. System identification and control. HERMES Edition.; Paris, 1993. 